\title{
Kidney Cancer pT4 TNM Finding v7
}

National Cancer Institute

\section{Source}

National Cancer Institute. Kidney Cancer pT 4 TNM Finding v7. NCI Thesaurus. Code C89293.

Kidney cancer with tumor invading beyond Gerota's fascia (including contiguous extension into the ipsilateral adrenal gland). (from AJCC 7th Ed.) 